\title{
Postpneumonectomy empyema: drainage by spontaneous oesophagopleural fistula
}

\author{
H HOLDT, S LIEBIG, A GABLER \\ From the Surgical Division, Department of Pulmonary Diseases, Heckeshorn Hospital, Berlin, West Germany
}

Oesophagopleural fistula after pneumonectomy is not as uncommon as the 49 previously published cases might suggest. Nevertheless, it presents a difficult therapeutic problem. Direct surgical repair of the fistula is the treatment of choice $^{1-7}$ as the mortality rate approaches $100 \%$ in patients who are not fit for surgery. This report describes the case of a patient who survived without surgical treatment as the fistula provided effective drainage of the empyema space.

\section{Case report}

In 1978 a 70 year old man underwent right pneumonectomy for a squamous cell carcinoma. His early recovery was uneventful but $\mathbf{1 0}$ days after operation he developed a bronchopleural fistula, which was followed shortly by empyema in the pneumonectomy space. The main microorganism cultured from the pleural fluid was Escherichia coli. The empyema was treated by tube drainage and antibiotics for six months, by the end of which the fistula had closed, and then by drainage and irrigation for a further two years. In January 1981, when the pleural fluid was sterile on culture, the chest tube was finally removed.

Four weeks later the patient consulted his private physician because of malaise and gastric symptoms. Gastrograffin swallow showed an oesophagopleural fistula situated at the lowest point of the empyema space, by which the empyema had obviously been discharged (fig 1). Chest radiographs confirmed a drop in the level of the pleural fluid, although the patient was still without a chest tube. Since his general condition did not allow a surgical attempt at direct closure of the fistula we tried unsuccessfully to close it by the oesophagoscopic application of fibrin glue. Subsequently the patient's condition improved spontaneously, though he was still without a chest tube. When a normal diet was restored his health continued to improve and he was discharged.

Two years later he is alive and in excellent health. Chest radiographs show that the pneumonectomy space is well drained and has shrunk to about one quarter of its original size. The oesophagopleural fistula remains in its original position but can only be demonstrated with the patient in

Address for reprint requests: Dr $\mathrm{H}$ Holdt, Chirurgische Abteilung der Lungenklinik Heckeshorn, Krankenhaus Zehlendorf, Am Grossen Wannsee 80, D-1000 Berlin 39, West Germany.

Accepted 7 March 1983 the lateral head down position (fig 2). He has gained $14 \mathrm{~kg}$ in weight and is not disturbed by the fistula.

\section{Discussion}

Oesophagopleural fistula occurs in $0.5 \%$ of cases of pneumonectomy for tuberculosis and carcinoma. ${ }^{2} \mathrm{CS}$ Twenty-seven cases have been described after pneumonectomy for tuberculosis, ${ }^{138-10}$ five after pneumonectomy for suppurative pulmonary disease, ${ }^{1}$ and 17 after pneumonectomy for carcinoma of the bronchus. ${ }^{24-6}$ Operative injury and chronic infection are believed to be the most important causes. Onset within three months of operation is likely to be due to direct injury to the oesophagus or its blood supply, especially if dissection was difficult. ${ }^{1}$ Late occurrence is related to chronic infection, ${ }^{1}$ usually in the form of empyema, which is often of long duration (for example, up to 24 years). ' Possible mechanisms for the development of the fistula are: (a) infection of the bronchial stump; (b) rupture of a peribronchial or perioesophageal abscess into the oesophagus; $(c)$ inflammation of the oesophageal wall; (d) erosion of suppurating lymph nodes into the oesophageal wall. ${ }^{12}$

In $94 \%$ of all cases of fistula after pneumonectomy the right pleural cavity is affected, as the proximity of the oesophagus to the right mediastinal pleura makes it more vulnerable to infection and trauma than the left side. ${ }^{14}$ Treatment is generally unsatisfactory and results are very disappointing. A cure rate of $21 \%$ can be achieved by early surgical closure of the oesophageal defect,' but in patients unfit for definitive surgery the mortality rate approaches $100 \% .^{12}$

In our case the fistula was caused by empyema that ruptured into the wall of the oseophagus. Unexpectedly, this did not cause serious complications but provided an effective drainage of the empyema space so that external drainage was not required.

\section{References}

' Takaro T, Walkup H, Okano T. Esophagopleural fistula as a complication of thoracic surgery. $J$ Thorac Cardiovasc Surg 1960;40:179-93.

${ }^{2}$ Evans J. Postpneumonectomy oesophageal fistula. Thorax 1972;27:674-7.

${ }^{3}$ Dumont A, De Graef J. La fistule oesophago-pleurale, complication tardive de la pneumonectomie. Lyon Chir 1961;57:481-8. 


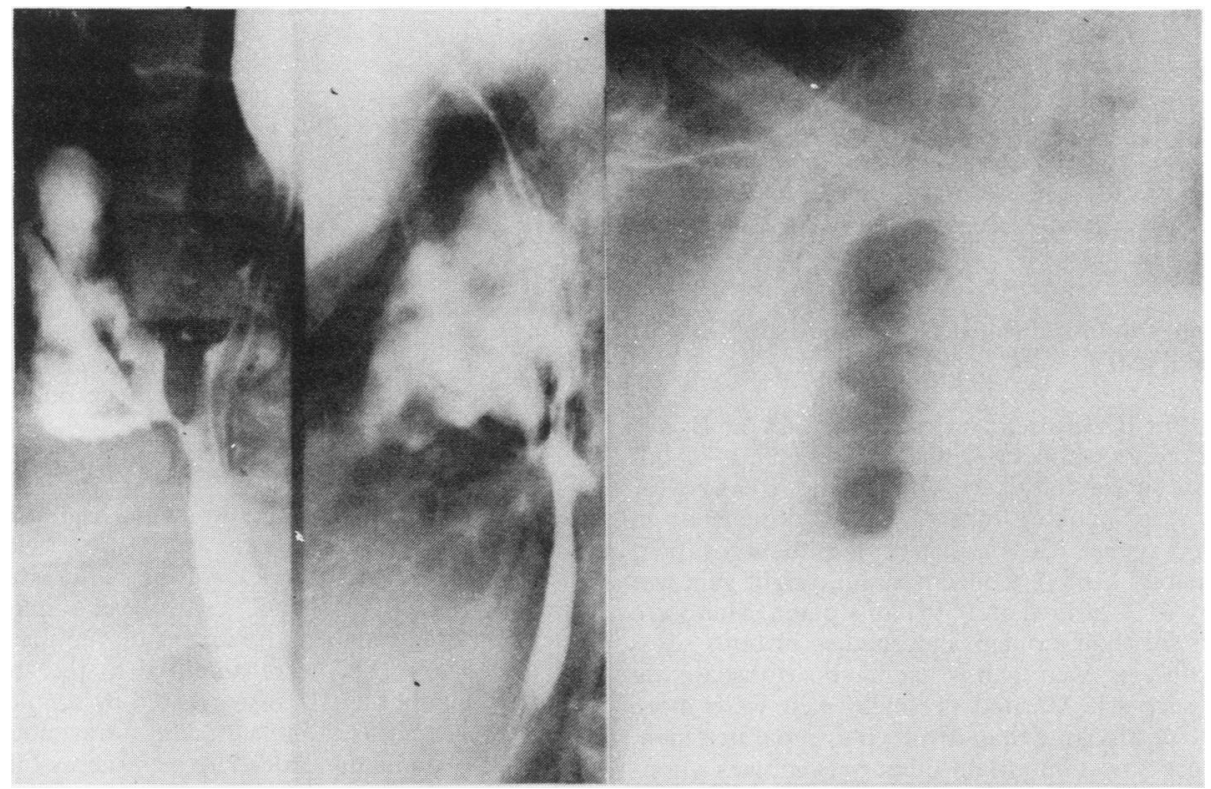

Fig 1 Oesophagopleural fistula two years seven months after right pneumonectomy.

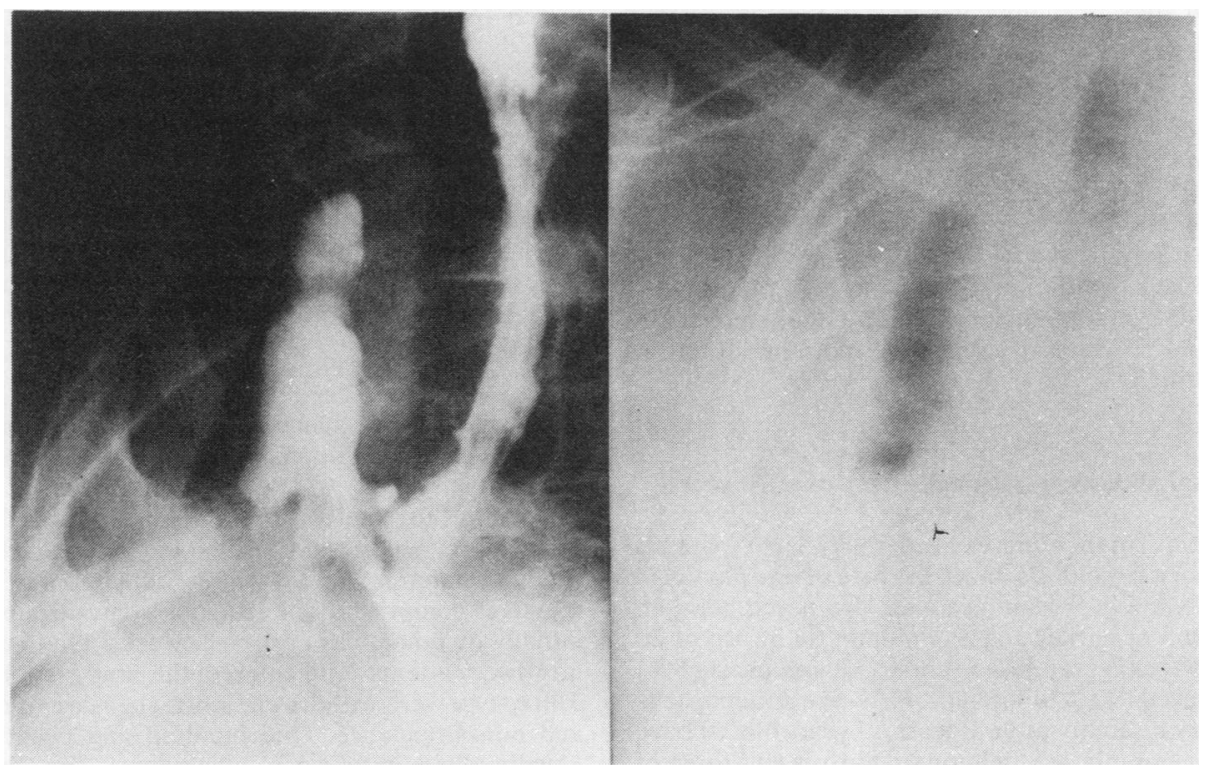

Fig 2 Oesphagopleural fistula 23 months after discovery and conservative treatment.

4 Benjamin J, Olsen A, Ellis J. Esophagopleural fistula: a rare postpneumonectomy complication. Ann Thorac Surg 1969;7:139-44.

${ }^{5}$ Engelmann R, Spencer F, Berg P. Postpneumonectomy esophageal fistula. J Thorac Cardiovasc Surg 1970;59:871-6.

- Efthimiadis M, Xanthakis D, Pirmikyrios N, Papadakis G, Aligizakis C. Late esophagopleural fistula after pneumonectomy for bronchial carcinoma. Chest 1974;65:579-80.

' Van den Bosch J, Swierenga J, Gelissen H, Laros C. Postpneumonectomy oesophagopleural fistula. Thorax
1980;35:865-8.

- Eriksen K. Oesophagopleural fistula diagnosed by microscopic examination of pleural fluid. Acta Chir Scand 1964;128:771-7.

- Santos M, Netto S, Marcal O. Fistula oesophagopleural traumática pós-pneumonectomia: análise de um caso tratado por esophagogastroplastia retrosternal. Rev Paul Med 1964;65:263.

${ }^{10}$ Pecora D, Brook R. Tuberculous fistula of the esophagus. J Thorac Surg 1958;36:53-7. 